\title{
Engineering future liveable, resilient, sustainable cities using foresight
}

Chris DF Rogers Eur Ing, BSC, PhD, CEng, MICE, MCIHT

Professor of Geotechnical Engineering, Director of the UKCRIC National

Buried Infrastructure Facility, University of Birmingham, Birmingham, UK

This paper shows how civil engineers can build better cities through a deeper understanding of the future benefits, resilience and value of their proposed urban infrastructure solutions. Three practical, foresight-based assessment methods are introduced and, for the first time, combined into a coherent design process founded on systems thinking. Based on data derived from a portfolio of research programmes, the University of Birmingham's 2014 Future Urban Living report and the findings from the UK government's Foresight Future of Cities project, they represent a synthesis of 15 years of research into sustainable, resilient and liveable cities. The three scenario-based methods provide a robust way for civil engineers to determine the likely performance and value of any future urban infrastructure scheme.

\section{Future context: understanding cities and urban systems}

Civil engineers diagnose and create solutions to city infrastructure problems that society faces now and those they anticipate facing in the future - for which a process of 'foresighting' must be adopted. However, there is a growing tension between the ever-increasingly rapid changes in the way cities, citizens and societies operate and the fact that civil engineers design and build infrastructure that is often required to function for decades, thus 'locking in' aspects of city systems and societal behaviour.

It is for this reason that the concepts of sustainability, resilience, adaptability and liveability now feature as design requirements. There is a compelling need, addressed in this paper, to support civil engineers in augmenting the way in which their interventions are conceived, designed and operated to align with these concepts and the prospect of radically different requirements for the far future.

The 'far future' is defined in this paper as a point in time beyond which current predictions and projections cannot be relied on. A 50-year time horizon is generally accepted as being sufficiently far advanced in societal terms, while longer time horizons are commonly used in environmental sciences (Evans et al., 2004).

However, predicting the far-future needs of cities must start with a deep understanding of the existing city context and its historical development (Rogers, 2017; p. 144), recognising that all cities are unique. Put simply, foresight must start with hindsight (GOfS, 2017b).

Reflecting this imperative, the UK Urban Living Partnership (RCUK, 2017), a current cross-research-council initiative, has focused on diagnosing the current problems in its five pilot cities; Birmingham, Bristol, Leeds, Newcastle and York. Appropriately, civil engineers are core members of four of the research programmes. However, it is the symbiotic collaboration with social and environmental scientists in this and previous initiatives (e.g. sustainable urban environments (SUE) (Leach et al., 2011) and living with environmental change (EPSRC, 2017a; ESPRC, 2017b)) that has enabled the holistic, systemic approach essential to addressing the challenges of future cities.

The pioneering aspect of the research is that social and environmental scientists were funded by the Engineering and Physical Sciences Research Council (EPSRC), their contribution being recognised as essential. The research outcomes have been enriched by breaking down disciplinary silos and the creation of a cohort of researchers that is able to work seamlessly across disciplinary boundaries (Leach et al., 2011).

For example, a particular lesson from the $£ 65$ million SUE programme concerns the tension between social science's imperative of fully defining the problem and engineering's imperative of moving rigorously towards a solution. Engineers tend to move towards a solution too quickly while social scientists tend to want to dwell on the problem, yet both activities are essential to an effective outcome, and a balance is necessary.

Equally, it is vital to appreciate the likely contextual changes that a city will experience, because they will influence the effectiveness of any engineering interventions conceived and implemented now. Two major initiatives over recent years were able to inform this thinking.

\subsection{Policy Commission on Future Urban Living}

The first - a 2014 University of Birmingham Policy Commission report entitled Future Urban Living (Rogers et al., 2014; University of Birmingham, 2017) - took a national and international view of likely contextual change. The 15 -strong commission of leading thinkers on cities (politicians, chief scientific advisors, practitioners, academics) took evidence from a wide range of those for whom cities provide the focus of their activities (city leaders, urban professionals, other stakeholders), and distilled it into a concise, yet nuanced, understanding of the needs of and aspirations for future cities and recommendations for how they might be realised.

The evidence was gathered by posing a set of common questions, to which the experts responded.

- What are the major challenges facing future urban living in the UK?

- What is your vision for your city (or cities generally) for 2050?

- What are the risks and uncertainties around achieving your vision for 2050?

- What characteristics should future urban centres have if they are to be effective places to live, work and play?

- What changes need to be made in, for example, governance, policy, public/private sector relationships, to ensure an acceptably good quality of future urban living can be achieved for all?

- What might be expected of us, collectively or individually, to make future urban living work? 
The responses, and subsequent open questioning and discussion, were recorded and transcribed, yielding several hundred-thousand words. These ideas were debated by the commissioners, clustered and distilled, stress tested with a separate group of independent leaders in city governance and practice, further debated and crystallised into a full report (25000 words), a summary report (1600 words) and recommendations (224 words).

Drawing analogies with physical and environmental sciences, the words from the transcribed interviews equate to the raw data from an experiment employing a range of sensors, from which the meaning (information, knowledge and wisdom) needs to be progressively distilled by processes of analysis. There is an analogy here to 'big data' and how it is interpreted to yield value.

A 'word cloud', in which the frequency of each word is represented by size, is a crude form of analysis. As can be seen from Figure 1, the original interviews represented much 'noise', while the progressive refinements into the full report and summary

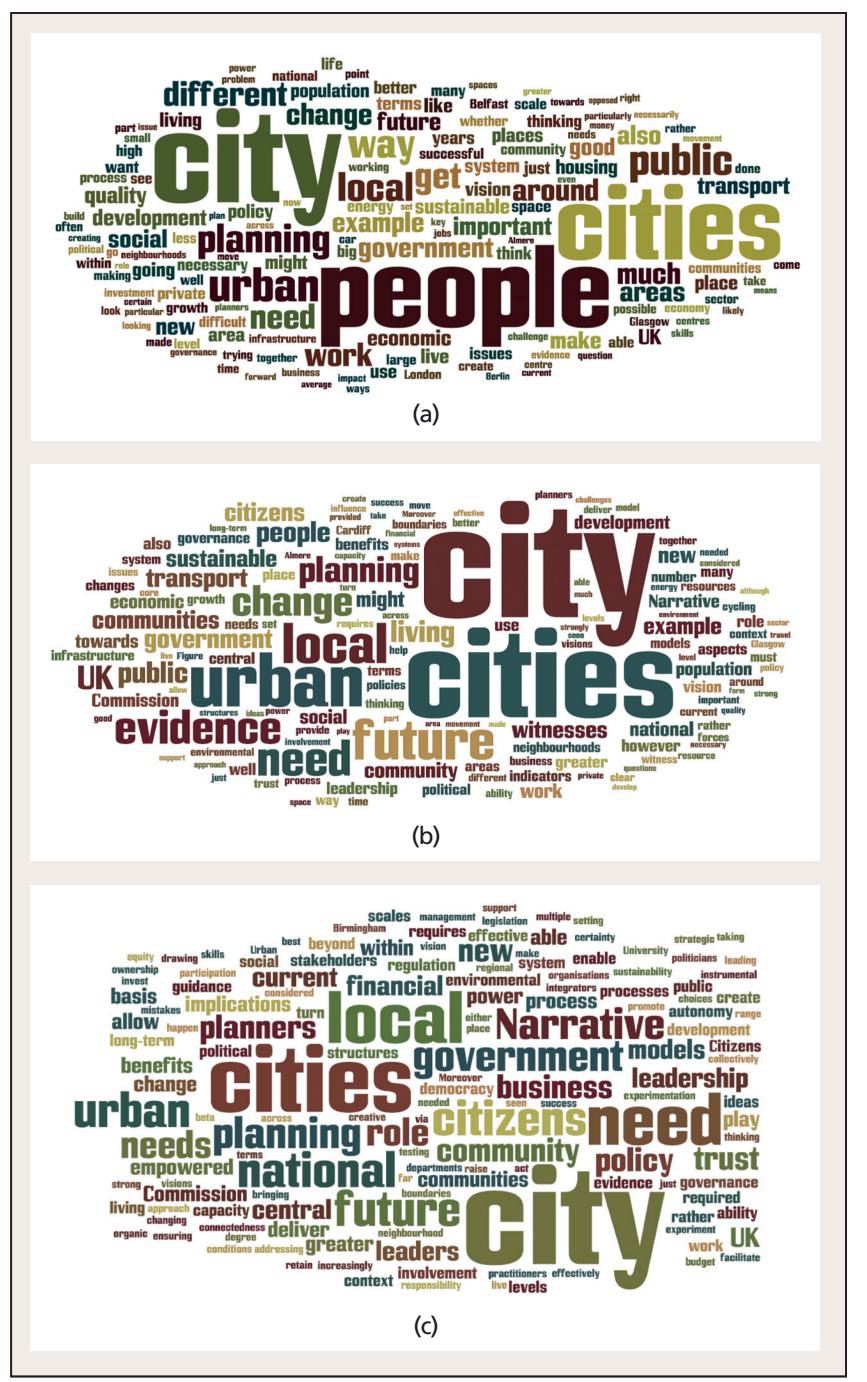

Figure 1. Word clouds representing frequency of terms used in the transcribed interviews (a), full report (b) and summary report (c) of the University of Birmingham's 2014 Future Urban Living report - emphasis and language change towards narrative, need and government as the information was analysed and refined report provided progressively cleaner, more refined word clouds in which ideas are distilled and the most relevant words selected to produce a nuanced set of arguments.

The filters in the process were the domain experts who carried out the analysis and synthesis, and reached a consensus on the essential meaning. Bias in the report was avoided by gaining consensus from a broadly constituted group of commissioners, who were set the challenge of producing an objective outcome, and the process of stress testing with a similarly broadly constituted group of leading thinkers.

\subsection{Foresight Future of Cities project}

In the same year, as part of a sequence of such projects (GoFS, 2017c), the Foresight Future of Cities project was launched. Forming one of its core findings, the UK Government Office for Science published its Future of Cities: Science of Cities report (GOfS, 2017a). It was produced by an eight-strong multidisciplinary expert group (including the author) and supported by a large project team. The objective was to assemble and review a comprehensive evidence base on future cities, with the aim of providing guidance to central and local government that takes cognisance of the future in today's policy development and decision-making.

The project viewed cities as highly complex, dynamic, multidimensional systems-of-systems that function at multiple temporal and spatial scales. It considered two time horizons: 2040, when projections from now might be used with some confidence, and 2065, when they would not, necessitating future scenario approaches (e.g. Hunt et al., 2012a; 2012b) to help understand the potential consequences of policies and decisions.

It adopted a systems-thinking approach and two primary focal points: the UK's system of cities and UK city systems. While cities, each having a unique history and context, provided one system boundary, it recognised that policies and decisions play out across a range of scales from neighbourhood, subcity, city, city region, regional and national to global.

Cities, or city regions, are usually best placed to shape and implement policies to greatest effect, because they are uniquely qualified to understand their own contexts. Nevertheless, national policies and actions are often necessary to remove barriers to allow this to happen, yet should be framed to facilitate local adaptation and allied to some degree of devolution of power and responsibility from central to local government.

Moreover, the project recognised that cities exist at the right scale for making changes that both deliver on sustainability, resilience and liveability agendas and formulate effective business models - they appreciate the multiple interdependencies between infrastructure and urban systems, which ultimately combine in the users of the services: the citizens in their local contexts.

The project team collected evidence by commissioning working papers and thought pieces on topics of importance and drawing on the work of many organisations - think tanks, universities, research centres and lobby groups. It visited 20 cities to understand their current contexts, needs and future aspirations, convened meetings with UK government departments and organised workshops with cohorts of experts (private finance, planners, designers, utility companies and other urban professionals).

The amalgamated evidence base is freely available on the UK government website (GOfS, 2017d) and is summarised in GOfS (2017e). Alongside topics of more specific economic and social focus, it includes substantial commissioned reports on urban form 
and infrastructure, a visual history of the future (Dunn et al., 2014), urban metabolism (Clift et al., 2015), ecosystem services, coping with change, comparative urban governance and city leadership. In addition, shorter thought pieces were commissioned on topics such as development underground, green infrastructure and health, beyond 'peak car', water and cities, and active travel.

The project team adopted six themes to assist with knowledge generation, collation and analysis. Three themes - how people live in cities, urban economies and governance structures - have a general relevance to civil engineering. The fourth theme, urban metabolism, and UK cities' sustainability and resilience in the context of resource security and climate change (GOfS, 2017f), is of more specific relevance. Aligning precisely to the current call by the Institution of Civil Engineers for research and development funding applications (Rogers et al., 2017), it addresses a fundamental challenge to civil engineers on responsible resource use (Leonard, 2010).

The fifth theme of ecosystem services (GOfS, 2017g; Ravetz, 2015) makes explicit the multiple benefits that the natural environment provides to cities and citizens, thereby enabling civil engineers specifically to support and augment, rather than replace, these services when engaging in their more routine responsibilities of enhancing, rather than compromising, the natural environment as a result of their work. The sixth theme - urban form - with its focus on restructuring cities, growing new places and evolving urban infrastructure systems, including physical and digital connectivity, is wholly germane (GOfS, 2017h).

While themes can help, silos do not. The project consequently adopted the mantra that all city systems are interdependent - a complex system-of-systems, reflecting Hall et al.'s (2013; 2016) approach to infrastructure engineering - while cross-cutting themes, such as 'technology', are potentially pervasive and could act as 'disruptors' to the normal evolution of city systems. The knowledge base comprises three detailed synthesis reports, 13 commissioned working papers and 21 essays, yet the contributions on construction materials (Purnell and Roelich, 2015) and smart infrastructure (Mair, 2015) are particularly worthy of note.

The policy commission and Foresight project and the very considerable volume of parallel (e.g. SUE, Living With Environmental Change, EU) research have provided vast knowledge bases from which to establish the likely and/or possible contextual changes that civil engineering designs should accommodate. Notably, the synthesis reports (GOfS, 2017a, 2017e; Rogers et al., 2014) have crystallised the thinking from many millions of words (raw data), ideas (information) and commissioned works (knowledge) into wisdom, using expert filters. The base material, the evidence, is still available for reinterpretation, representing a robust foundation on which to base predictions and projections, to establish robust scenario methodologies and to ask 'what if?' questions when creating engineering designs. The parallel to physical science and engineering experiments is clear and evident.

One simple example relates to anticipated UK population growth, which is projected to increase by around 10 million soon after 2040 (ONS, 2016): where will they be accommodated? To emphasise the need for strategic thinking using a 'what if?' approach (i.e. in no way suggesting a trend or a preference), the Foresight project considered three scenarios - the majority of this increase housed in London and south-east England, or distributed among the major cities, or distributed uniformly in the 64 primary urban areas (Figure 2; GOfS, 2017i) - with profound implications for how civil engineers should design local and national infrastructure systems.
The challenge here is either to create designs that are sufficiently adaptable - nimble - to operate effectively now and yet accommodate such potential change, or to design policy interventions that would shape the future settlement patterns, or to create a combination of the two. A piecemeal approach is unlikely to be efficient or effective.

Exemplary research exploring projected scenarios has been conducted by the Infrastructure Transitions Research Consortium (Hall et al., 2014; Infrastructure Transitions Research Consortium, 2017), work that is essential and defensible but arguably insufficient. This paper argues for the use of extreme far-future scenarios - that is, those freed from current contextual constraints - while the Foresight Future of Cities project team would advocate a wide range of 'foresighting' techniques to assist in understanding possible futures (GOfS, 2017b).

\section{Engineering sustainable, resilient and liveable future cities}

Civil engineers are required to embrace sustainability, resilience, adaptability, liveability and smartness.

Sustainability - meeting the needs of the present, without compromising the ability of future generations to meet their own needs (Bruntland, 1987) - introduces social, economic and environmental perspectives to designs, a concept that has become progressively enriched and more nuanced (Ainger and Fenner, 2014; Lombardi et al., 2011a) and for which there is much guidance (McGregor and Roberts, 2003; Pearce et al., 2012).

Resilience, which supplements sustainability, or for some provides a dominant focus, depending on its definition (Rogers et al., 2012a), often has strong environmental, especially climate change, connotations. However, an intervention 'continuing to function, and deliver its benefits, in the face of change' (no matter the rate of change; Lombardi et al., 2012) provides greatest clarity.

Adaptability is the civil engineer's response to the need to design in resilience, while liveability (Leach et al., 2013) and smartness emphasise the centrality of citizens and society to urban engineering, enabled by technology (Cavada et al., 2014), although smartness should be for a purpose other than simply efficiency (Cavada et al., 2016).

Three methodologies have been developed to enable engineers and other urban professionals to deliver the above agenda and, due to their consistency of approach, are combined for the first time in

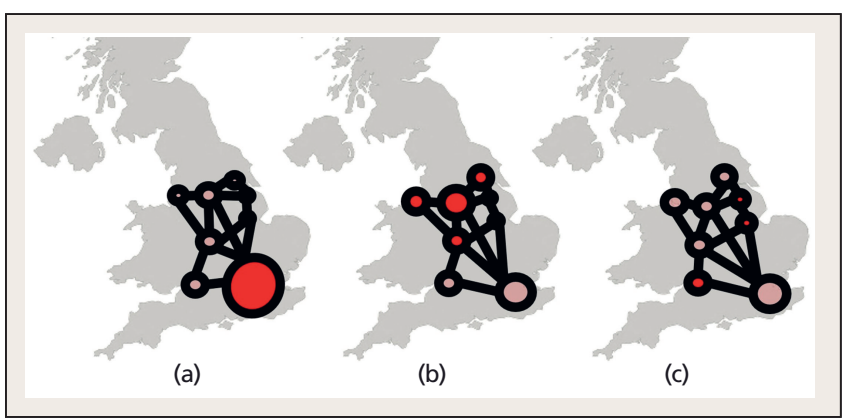

Figure 2. Three potential scenarios for accommodating future UK population growth: London-centric (a), major city empowerment (b) and smaller cities focus (c) 
this paper (Figure 3). They all test the efficacy of civil engineering interventions using extreme future scenarios, a technique with the compelling advantage of removing constraints of thinking that would apply when attempting to extrapolate from the current context.

The assessment involves 'parachuting into' the new world, so all thoughts of 'one cannot do this because of current regulations/ societal norms/citizen attitudes/design practices' are immediately dispelled. It is how each of these considerations applies to the future world in question that is important; so, for example, what would the societal norms and citizen attitudes be in these worlds?

\section{1 "Designing Resilient Cities" method}

The 'Designing Resilient Cities' method (formerly the 'urban futures' method - Lombardi et al., 2012; Rogers et al., 2012b) assesses the resilience of a civil engineering intervention conceived and implemented now, whether it is a policy, practice, constructed artefact, system, process or behaviour change (noting that a combination is sometimes required; Hunt et al. (2013)).

It does so by testing the intervention both in the current context and in four extreme yet plausible scenarios developed by the Global Scenarios Group (Electris et al., 2009; Raskin 2005; Raskin et al., 1998, 2002, 2010) - market forces, fortress world, policy reform and new sustainability paradigm. These are worlds in which society operates in a recognisable manner (e.g. as seen in history or different parts of the world now), yet each of which exists at the extremes of a future 'plausibility space' in different directions of travel. They have been exhaustively characterised by Lombardi et al. (2012) and exist solely to enable the intervention to be tested; they are not treated as preferred or unwanted directions of travel.

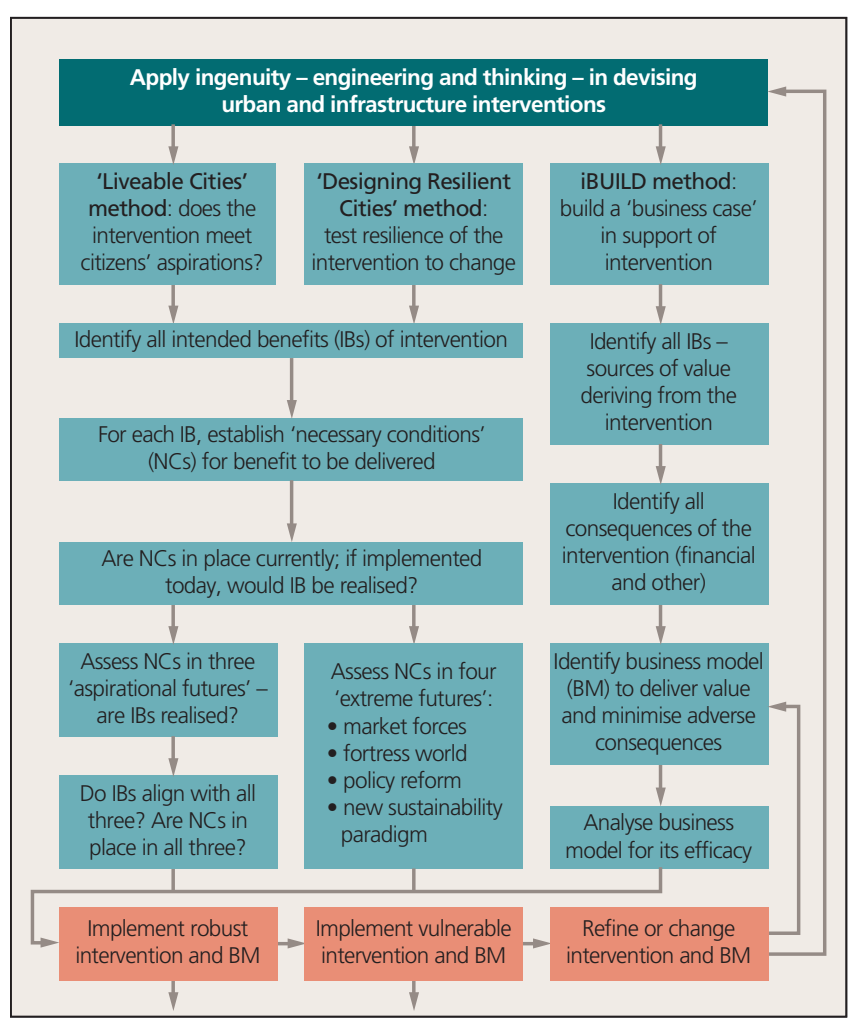

Figure 3. Flow chart showing assessment of a civil engineering intervention using liveability, resilience and investment analyses

\section{2 “Liveable Cities" aspirational futures method}

The 'Liveable Cities' aspirational futures method assesses whether an intervention meets the cities' and citizens' aspirations (Leach et al., 2017a) by establishing, by way of citizens and/or their representatives and those who govern and operate cities, a comprehensive set of city aspirations. These aspirations are clustered under the three (economic, social, environmental) pillars of sustainability.

Each cluster is then considered in turn as the sole set of guidelines on which to develop three far-future visions for the particular city (GOfS, 2017j; Hunt and Rogers, 2015a, 2015b, 2015c). Synthesis between these three extreme visions shows where interventions, or policies, are likely to work; conflicts show potential vulnerabilities and opportunities for changing the intervention.

\section{3 'IBUILD' method}

The 'iBUILD' method assesses alternative business models to underpin investment in the intervention (Dawson et al., 2014; iBUILD, 2017a) by establishing all forms of value that might be generated by an intervention, and establishing for whom the value is realised (now and in the future). The outcome is then matched to alternative forms of investment; a database of 140 different types of local infrastructure business model enables alternatives to be chosen for testing (iBUILD, 2017b).

All three methods start by developing a deep understanding of both the problem (approaching this from the perspectives of all relevant stakeholders) and the context, and applying ingenuity to produce a solution - a civil engineering intervention - or a range of alternative solutions (Figure 3). Each proposed intervention is analysed for all its potential benefits: all the forms of value that it might realise (social, environmental, direct economic, indirect economic, cultural, political, etc.) and all adverse consequences that it might minimise (social harm, environmental harm, etc.), thinking beyond the narrow confines of the design brief. Figures 4 and 5 provide examples.

From this foundation, the methods can be integrated. To test for resilience: taking each 'intended benefit' in turn, the 'necessary conditions' for the benefit to be delivered are identified. For example, if the intervention were a footpath and the intended benefit is to facilitate routine pedestrian access between two locations, the necessary conditions would include whether there is a demand for such access, it would be considered safe, the surface remains serviceable in all weathers, it is aesthetically pleasing and so on: will it deliver its function and will this function be exploited?

The intervention is analysed in its current context to determine whether it would be successful now (the necessary conditions are in place) and then in the extreme futures. If the necessary conditions exist now and in all futures, the intervention is robustly conceived and can be implemented; if some necessary conditions are lacking, the intervention's vulnerabilities are made explicit and either implementation can occur in the knowledge that it might be vulnerable to contextual change or the intervention can be redesigned and retested.

References to a 'robust intervention' are made in the figures to indicate that it is not 'vulnerable' to contextual change - that is to the possibility that necessary conditions might not remain in place for the intervention to deliver its benefits or value. If it is vulnerable to such a changing context, the intervention can still be implemented, but in the knowledge that it might not realise its full potential.

Similarly, the intervention is assessed for alignment with the cities' and citizens' aspirations. Once finalised, alternative business models can be explored to enable implementation, noting that if no suitable model can be found, the intervention itself might need further 
iteration. Indeed iteration is essential and should be considered at every level in Figures 3-5: as benefits are being identified, revision of the intervention is possible, for example, and there is no reason why such refinements by iteration should not be embraced as the methodologies are being applied. However, for simplicity the processes are described using iteration once each full analysis has been completed.

\section{Discussion}

The need for contextual understanding of cities arises from specific urban diagnostics research, 'city observatory' activities and analysis of big data (noting that, like materials, data quality degrades with time, only more rapidly), from which assessment methods extract the critical influencing factors (Leach et al., 2016, 2017a, 2017b). Crucially, a civil engineer must work seamlessly across disciplinary silos to embrace social, environmental, political and cultural perspectives, with an appreciation of their languages and methods of working.

The approaches advocated in this paper of understanding the current context, devising interventions, testing them in extreme future scenarios, refining them, devising appropriate business models and further iteration, and using the outcomes alongside more traditional projections and foresighting techniques, provide transparently defensible methods of reducing uncertainty and risk when engineering for future cities.

Alongside this is a need to engineer the systems of governance - from the formal (legislation, regulation, codes and standards) to the informal (citizen attitudes, societal norms, user behaviours) - to ensure that a civil engineering intervention works effectively now and into the far future. This is not 'for someone else to do'; it is incumbent on the civil engineer to establish these governance system needs, to make them explicit when communicating their designs and to seek to facilitate change where it is necessary.

Indeed, transparency is the underlying principle behind all three methods - in identifying all of the multiple benefits (hence forms of value) that could be achieved by an intervention, and refining designs both to offer and ensure the delivery of greatest value into the far future, provides the transformative step that this paper offers. This paper's primary ambition is to change the reader's mindset, if necessary, to one of perennially seeking to enhance social, environmental and cultural benefits from designs that are almost always constrained by economic considerations - and thereby conform to the principles of sustainability, resilience and liveability.

The examples in Figures 4 and 5 demonstrate the type of systems thinking - revoking the siloed thinking that often limits the value achieved from, hence design of, interventions and the business models that constrain them - for which engineers strive and yet for which there is no transparent and repeatable route to its achievement. The methods combined in Figure 3 aim to provide such a route.

The simple beam design example in Figure 4 extends the designer's responsibilities. Before this is dismissed as wishful, or perhaps unwished for, thinking, it is necessary to consider when in the decision-making process for a beam, or for an intervention in cities, the civil engineer should engage.

Agreeing an intervention's objectives and how they relate to sustainability, resilience and liveability - aspirational - goals (Hunt et al., 2008a), ensuring they feature throughout the development timeline (Hunt et al., 2008b) and understanding where tensions arise and where trade-offs are required (Lombardi et al.,2011b; Rogers et al., 2008) so that the aspirational goals do not get 'locked out' and design

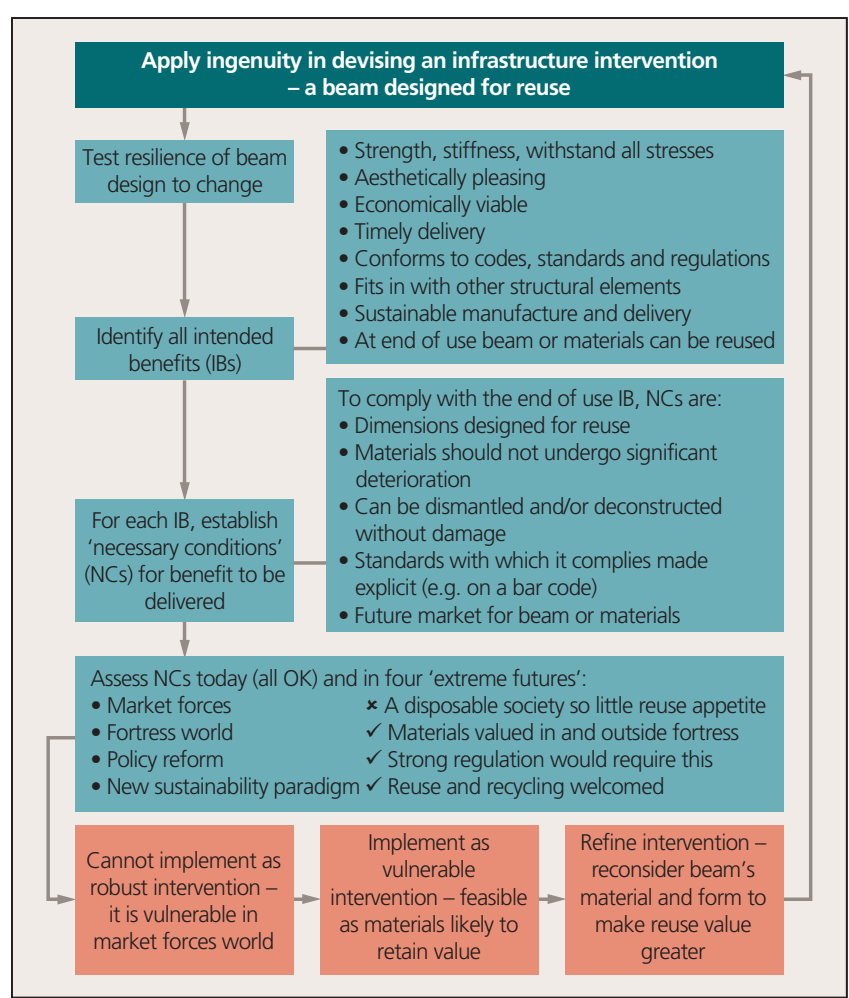

Figure 4. Resilience assessment of a beam designed for reuse

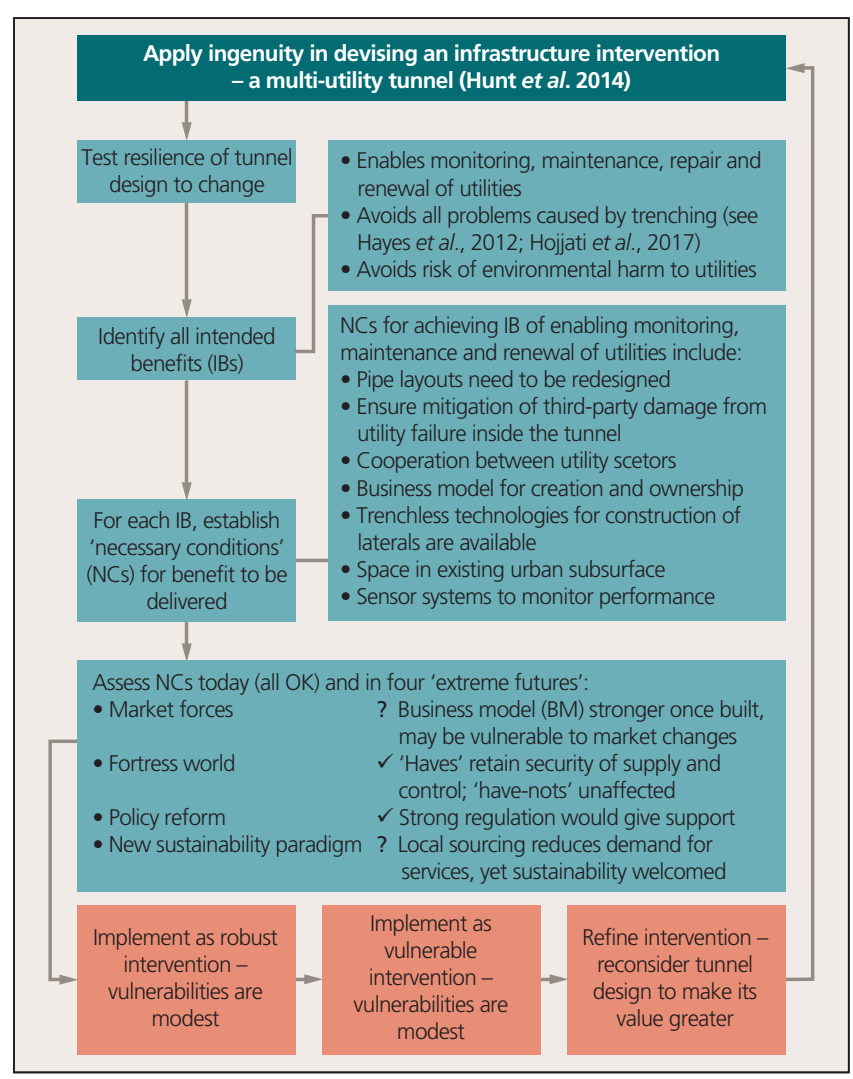

Figure 5. Example resilience assessment of a multi-utility tunnel 
thinking is constrained (Leach et al., 2014), is essential. Establishing how they influence a city's performance - another big ambition of the Liveable Cities project - is equally crucial and this can be achieved using 345 city performance parameters (see Leach et al., 2017a).

One final observation is that the methods are designed to aid decision-making, not to make decisions. They remove no responsibility from the engineer, but prompt wider thinking of the civil engineering intervention in the context in which it is expected to perform. While the evidence base referred to in this paper is largely UK based, the methods can be readily translated to any context internationally, the essential requirement being to understand as fully as possible the context. This includes the geographical, cultural and political setting, and specifically all of the forms of governance that are relevant to the place in question: from the more formal (legislation, regulation, taxation) to the informal (societal attitudes, social norms, user behaviours).

The most obvious way of achieving a comprehensive contextual understanding is to use system mapping techniques to establish the dependencies and interdependencies between the system of interest, that in which the intervention is proposed, and the other urban systems with which it interacts (e.g. see Bouch and Rogers, 2017).

\section{Conclusions}

Synthesis of three synergistic far-future scenario methods - assessing resilience, alignment with aspirations and value propositions - with learning from a substantial research portfolio and two future cities evidence-gathering initiatives provides the basis for reducing the inherent risk and uncertainty of engineering city interventions that need to be effective both now and in the far future.

Crucially, none of the methods aims to provide 'a solution'; they remove none of the responsibility and provide no constraint, but rather provide enablers of more informed, and assured, thinking, and facilitate the inclusion of sustainability, resilience, adaptability and liveability. Moreover, the process of working with scenarios directly aids broader thinking on the proposed intervention, creates new ideas and assists in shaping its implementation.

The design thinking described in this paper aims to enrich, empower and future-proof current civil engineering interventions in cities. As the different examples demonstrate, they can all be employed simply and straightforwardly or using detailed, more rigorous approaches (the 'Liveable Cities' method uses 345 city performance parameters; the 'Designing Resilient Cities' method examines extreme future performance using 100 urban characteristics; a city's aspirational futures are established via a broadly-constituted workshop; alternative business models are drawn from $\sim 140$ alternatives).

This paper uniquely synthesises three methods to offer a combined approach that provides a means of addressing a civil engineer's core challenge - ensuring that current ingenuity in creating long-lasting outcomes remains of value no matter how the future develops.

\section{Acknowledgements}

The author gratefully acknowledges the financial support of the EPSRC under grant numbers GR/S20482, EP/C513177 and EP/E021603 (Birmingham Eastside Regeneration - Sustainable Urban Redevelopment), EP/F007426 (Urban Futures), EP/I016133 (Resilience of Critical Local Transport and Utility Infrastructures),
EP/J017698 (Liveable Cities), EP/K012699 (Assessing the Underworld), EP/K012398 (iBUILD), EP/N010523 (SelfRepairing Cities) and EP/P002021 (Urban Living Birmingham), and the inspiration, knowledge and wisdom passed on by all those with whom he has worked in these research grants. He also gratefully acknowledges the members of the ICE Futures Group, with whom many interesting debates have been had.

\section{References}

Ainger C and Fenner RA (2014) Sustainable Infrastructure - Principles Into Practice. ICE Publishing, London, UK.

Bouch CJ and Rogers CDF (2017) A systems thinking approach to the development of alternative infrastructure business models. Proceedings of International Symposium on Next Generation Infrastructure (ISNGI 2017). ISNGI, London, UK.

Bruntland GH (1987) Our Common Future. Oxford University Press, Oxford, UK.

Cavada M, Hunt DVL and Rogers CDF (2014) Smart cities: contradicting definitions and unclear measures. Proceedings of 4 th World Sustainability Forum, November. Sciforum Electronic Conferences Series. See http:// www.sciforum.net/presentation/1021 (accessed 19/11/2017).

Cavada M, Hunt DVL and Rogers CDF (2016) Do smart cities realise their potential for lower carbon dioxide emissions? Proceedings of the Institution of Civil Engineers - Engineering Sustainability 169(6): 243-252.

Clift R, Druckman A, Christie I, Kennedy C and Keirstead J (2015) Urban Metabolism: A Review in the UK Context. Foresight. Government Office for Science, London, UK.

Dawson RJ, Walsh CL, Purnell P and Rogers CDF (2014) Briefing: Infrastructure business models, valuation and innovation for local delivery. Infrastructure Asset Management 1(3): 66-67.

Dunn N, Cureton P and Pollastri S (2014) A Visual History of the Future. Foresight. Government Office for Science, London, UK.

Electris C, Raskin P, Rosen R and Stutz I (2009) The Century Ahead: Four Global Scenarios Technical Documentation. Tellus Institute, Boston, MA, USA.

EPSRC (Engineering and Physical Sciences Research Council) (2017a) EPSRC Review of the SUE and ARCC Programmes. EPSRC, Swindon, UK. See http:// www.epsrc.ac.uk/newsevents/pubs/suearccreview/ (accessed 19/11/2017).

EPSRC (2017b) Living With Environmental Change. EPSRC, Swindon, UK. See http://www.epsrc.ac.uk/research/ourportfolio/themes/ livingwithenvironmentalchange (accessed 19/11/2017).

Evans E, Ashely R, Hall J et al. (2004) Foresight Future Flooding, Volume I and Volume II. UK Office of Science and Technology, London, UK.

GOfS (Government Office for Science) (2017a) Future of Cities: Science of Cities. See http://www.gov.uk/government/publications/future-of-citiesscience-of-cities (accessed 19/11/2017)

GOfS (2017b) Future of Cities: Foresight for Cities. See http://www.gov.uk/ government/publications/future-of-cities-foresight-for-cities (accessed 19/11/2017).

GOfS (2017c) Foresight Projects. See http://www.gov.uk/government/ collections/foresight-projects (accessed 19/11/2017).

GOfS (2017d) Future of Cities. See http://www.gov.uk/government/ collections/future-of-cities (accessed 19/11/2017).

GOfS (2017e) Future of Cities: Overview of Evidence. See http://www. gov.uk/government/publications/future-of-cities-overview-of-evidence (accessed 19/11/2017).

GOfS (2017f) Future of Cities: Urban Metabolism. See http://www.gov.uk/ government/publications/future-of-cities-urban-metabolism (accessed 19/11/2017).

GOfS (2017g) Future of Cities: Ecosystem Services. See http://www.gov.uk/ government/publications/future-of-cities-ecosystem-services (accessed 19/11/2017).

GOfS (2017h) Future of Cities: Urban Form and Infrastructure. See http:// www.gov.uk/government/publications/future-cities-urban-form-andinfrastructure (accessed 19/11/2017).

GOfS (2017i) Future of Cities: UK Scenarios. See http://www.gov.uk/ government/publications/future-of-cities-uk-scenarios (accessed 19/11/2017). 
GOfS (2017j) Future of Cities: Aspirational Scenarios. See http://www.gov.uk/ government/publications/future-of-cities-aspirational-scenarios (accessed 19/11/2017).

Hall JW, Henriques JJ, Hickford AJ and Nicholls RJ (2013) Systems-of-systems analysis of national infrastructure. Proceedings of the Institution of Civil Engineers - Engineering Sustainability 166(5): 249-257.

Hall JW, Hendriques JJ, Hickford AJ et al. (2014) Assessing the long-term performance of cross-sectoral strategies for national infrastructure. Journal of Infrastructure Systems 20(3): 04014014

Hall JW, Tran M, Hickford AJ and Nicholls RJ (2016) The Future of National Infrastructure: A System-of-Systems Approach. Cambridge University Press, UK.

Hayes R, Metje N, Chapman DN and Rogers CDF (2012) Sustainability Assessment of Streetworks. Proceedings of the Institution of Civil Engineers - Municipal Engineer 165(4): 193-204.

Hojjati A, Jefferson I, Metje N and Rogers CDF (2017) Sustainability assessment for urban underground utility infrastructure projects. Proceedings of the Institution of Civil Engineers - Engineering Sustainability, https://doi.org/10.1680/jensu.16.00050.

Hunt DVL and Rogers CDF (2015a) Aspirational City Futures: A Short Review of Foresight Approaches. Foresight, Government Office for Science, London, UK. Hunt DVL and Rogers CDF (2015b) Aspirational City Futures: 3 Models for City Living. Foresight, Government Office for Science, London, UK.

Hunt DVL and Rogers CDF (2015c) Aspirational City Futures: 3 Models for City Living - Workshops (Bristol and Birmingham). Foresight, Government Office for Science, London, UK.

Hunt DVL, Lombardi DR, Rogers CDF and Jefferson I (2008a) Application of sustainability indicators in decision-making processes for urban regeneration projects. Proceedings of the Institution of Civil Engineers Engineering Sustainability 161(1): 77-91.

Hunt DVL, Lombardi DR, Jefferson I and Rogers CDF (2008b) The development timeline framework: a tool for engendering sustainable use of underground space. In GeoCongress 2008: Geosustainability and Geohazard Mitigation, vol. 178 (Reddy KR, Khire MV and Alshawabkeh AN (eds)). American Society of Civil Engineers, VA, USA, pp. 859-866.

Hunt DVL, Lombardi DR, Atkinson S et al. (2012a) Using scenarios to explore urban UK futures: a review of the literature 1998 to 2011 - monograph. In Designing Resilient Cities: A Guide to Good Practice (EP103 Supplement CD-ROM). IHS BRE Press, Berkshire, UK

Hunt DVL, Lombardi DR, Atkinson S et al. (2012b) Scenario archetypes: converging rather than diverging themes. Sustainability 4(4): 740-772.

Hunt DVL, Jefferson I and Rogers CDF (2013) Scenarios analysis through a futures performance framework. Proceedings of the Institution of Civil Engineers - Engineering Sustainability 165(5): 258-271.

Hunt DVL, Nash D and Rogers CDF (2014) Sustainable utility placement via multi utility tunnels. Tunnelling and Underground Space Technology 39: 15-26.

iBUILD (2017a) Infrastructure business models, valuation and innovation for local delivery. Valuing Infrastructure Conference. See https://conferences. leeds.ac.uk/valuing-infrastructure/programme/ (accessed 19/11/2017).

iBUILD (2017b) https://research.ncl.ac.uk/ibuild/ (accessed 19/11/2017).

Infrastructure Transitions Research Consortium (2017). See http://www.itrc. org.uk (accessed 19/11/2017).

Leach JM, Rogers CDF, Cooper RFD, Cooper I and Luger J (2011) Sustainable Urban Environments Research Dialogues. EPSRC, Swindon, UK.

Leach JM, Lee SE, Braithwaite PA et al. (2013) What makes a city liveable? Implications for next-generation infrastructure services. In Proceedings of International Symposium for Next Generation Infrastructure, Wollongong, Australia, 1-4 October, pp. 397-405.

Leach JM, Boyko CT, Cooper RFD et al. (2014) Do sustainability measures constrain urban design creativity? In Proceedings of the Institution of Civil Engineers - Urban Design and Planning 168(1): 30-41.

Leach JM, Braithwaite PA, Lee SE et al. (2016) Measuring urban sustainability and liveability performance: the City Analysis Methodology (CAM). International Journal of Complexity in Applied Science and Technology 1(1): 86-106.

Leach JM, Lee SE, Hunt DVL and Rogers CDF (2017a) Improving city-scale measures of livable sustainability: A study of urban measurement and assessment through application to the city of Birmingham, UK. Cities 71: 80-87.

Leach JM, Lee SE, Boyko CT et al. (2017b) Dataset of the livability performance of the city of Birmingham, UK, as measured by its citizen wellbeing, resource security, resource efficiency and carbon emissions. Data in Brief 15: 691-695.
Leonard A (2010) The Story of Stuff: How our Obsession with Stuff is Trashing the Planet, our Communities, and our Health - and a Vision for Change. Constable and Robinson, London, UK.

Lombardi DR, Porter EJ, Barber ARG and Rogers CDF (2011a) Conceptualising sustainability in UK urban regeneration: a discursive formation. Urban Studies 48(2): 273-296.

Lombardi DR, Caserio M, Donovan R et al. (2011b) Elucidating sustainability sequencing, tensions and trade-offs in development decision-making. Environment and Planning B, Planning and Design 38(6): 1105-1121.

Lombardi DR, Leach JM and Rogers CDF et al. (2012) Designing Resilient Cities: a Guide to Good Practice. IHS BRE Press, Berkshire, UK.

Mair RJ (2015) How Will City Infrastructure and Sensors be Made Smart? Foresight, Government Office for Science, London, UK. See https:// www.gov.uk/government/uploads/system/uploads/attachment_data/ file/443531/future-cities-smart-infrastructure.pdf (accessed 19/11/2017)

McGregor A and Roberts C (2003) Using the SpearTM assessment tool in sustainable master planning. In Proceedings of US Green Building Conference (Kibert CJ (ed.)). US Green Building Council, Pittsburgh, PA, USA, pp. 1-12.

ONS (Office for National Statistics) (2016) Results, 2014-based National Population Projections Reference Volume. ONS, London, UK. See http:// www.ons.gov.uk (accessed 10/11/2017).

Pearce OJD, Murry NJA and Broyd TW (2012) Halstar: systems engineering for sustainable development. Proceedings of the Institution of Civil Engineers - Engineering Sustainability 165(2): 129-140.

Purnell P and Roelich KE (2015) What will Cities of the Future be Made of? Foresight, Government Office for Science, London, UK. See https://www.gov.uk/government/uploads/system/uploads/attachment data/file/452920/future-cities-materials.pdf (accessed 19/11/2017).

Raskin P (2005) Global scenarios and the millennium ecosystem assessment: an historic overview. Ecosystems 8(2): 133-142.

Raskin P, Gallopin G, Gutman P, Hammond A and Swart R (1998) Bending the Curve: Toward Global Sustainability. PoleStar Series Report no. 8. Stockholm Environment Institute, Stockholm, Sweden.

Raskin P, Banuri T, Gallopin G et al. (2002). Great Transition: The Promise and Lure of the Times Ahead. PoleStar Series Report no. 10. Stockholm Environment Institute, Stockholm, Sweden.

Raskin P, Electris C and Rosen RA (2010) The century ahead: searching for sustainability. Sustainability 2(8): 2626-2651.

Ravetz J (2015) The Future of the Urban Environment and Ecosystem Services in the UK. Foresight, Government Office for Science, London, UK

RCUK (Research Councils UK) (2017) Urban Living Partnership. See http:// www.rcuk.ac.uk/research/xrcprogrammes/urban-living-partnership/ (accessed 19/11/2017).

Rogers CDF (2017) The value of foresight and scenarios in engineering liveable future cities. In Retrofitting Cities for Tomorrow's World (Eames M, Dixon T, Hunt M and Lannon S(eds)). Wiley Blackwell, Chichester, UK, pp. 139-152.

Rogers CDF, Lombardi DR, Barber ARG, et al. (2008) Implementing Sustainability - Lessons for Urban Regeneration. University of Birmingham, UK. See http://www.esr.bham.ac.uk (accessed 19/11/2017).

Rogers CDF, Bouch CJ, Williams S et al. (2012a) Resistance and resilience paradigms for critical local infrastructure. Proceedings of the Institution of Civil Engineer - Municipal Engineer 165(2): 73-84.

Rogers CDF, Lombardi DR, Cooper RFD and Leach JM (2012b) The urban futures methodology applied to urban regeneration. Proceedings of the Institution of Civil Engineers - Engineering Sustainability 165(1): 5-20.

Rogers CDF, Shipley J, Blythe P et al. (2014) Future Urban Living - A Policy Commission Investigating the Most Appropriate Means for Accommodating Changing Populations and their Needs in the Cities of the Future. University of Birmingham, Birmingham, UK.

Rogers CDF, Hunt DVL, Leach JM, Purnell P and Roelich KE (2017) Briefing: Resource scarcity and resource security - a suppressed civil engineering challenge. Proceedings of the Institution of Civil Engineers - Waste and Resource Management 166(2): 49-51.

University of Birmingham (2017) Policy Commission on Future Urban Living. See http://www.birmingham.ac.uk/research/impact/policy-commissions/ future-urban-living (accessed 19/11/2017) 